\title{
Design of Yacht Course Controller
}

\author{
Pan Weigang ${ }^{*}$ and Xiao Hairong
}

Department of Information Science \& Electronic Engineering, Shandong Jiaotong University, Shandong Jinan, 250357, P.R. China

\begin{abstract}
The strong non-linearity and uncertainty has an impact on autopilot dynamic constraints and wave interference. So, it is formidable to design yacht course controller with excellent performance. For this, a non-linear control strategy of active disturbance rejection is suggested, and the adaptive ability of the auto disturbance rejection controller is improved on line by genetic algorithm. Experiment shows the yacht heading controller has strong robustness and adaptability to environmental interference.
\end{abstract}

Keywords: Active disturbance rejection controller, genetic algorithm, yacht course.

\section{INTRODUCTION}

Yachts autopilot will execute the design optimization process, saving a lot of energy, manpower and time.

The PID algorithm is applied to the ship course control, while it is sensitive to the high frequency interference, resulting in the frequent movement of the rudder, and lack of ships and marine dynamic conditions adequacy. Adaptive control, with high costs, parameter adjustment difficulties, in addition to non-linear vessels, cannot ensure good control effect.

Active Disturbance Rejection Controller (ADRC), does not depend on the plant model. It is a non-linear solution, an effective method of strong uncertain interference, coupling with large delay. However, the ADRC requires a lot of arguments, and selecting parameters with a great relationship. ADRC requires adjusting some parameters to be online, to overcome the inconvenience, due to changes in the actual operation and parameters. Such a method is called a genetic algorithm.

This paper presents a new anti-rejection control technology and simulation research yacht heading controller type, since genetic algorithm showed good results in the yacht and environmental parameter perturbations [1-6].

\section{YACHT STEERING MODEL AND DISTURBANCE MODEL}

\subsection{Yacht Model}

Yacht control mathematical model is as follows.

*Address correspondence to this author at the Department of Information Science \& Electronic Engineering, Shandong Jiaotong University, Shandong Jinan, 250357, P.R. China; Tel: +86 531 80687935;

Fax:+86 531 80687935; E-mail: panweigang1980@163.com

$$
\left\{\begin{array}{l}
m\left(\dot{u}_{G}-v_{G} r\right)=X \\
m\left(\dot{v}_{G}+\dot{u}_{G} r\right)=Y \\
I_{Z Z} \dot{r}=N-x_{G} Y
\end{array}\right.
$$

where,

$$
m \text { : Yacht Quality }
$$

$I_{Z Z}$ : The yacht movement of inertia of the yawing moment

$u_{G}:$ yacht longitudinal speed

$v_{G}:$ yacht horizontal speed

$r$ : yacht turn head angular velocity

$x_{G}$ : the longitudinal coordinates of the center of the ship in the attached coordinate system

$X, Y$ : external force acting on the hull

$N:$ the external torque acting on the hull

$$
\left\{\begin{array}{l}
X=\left(X_{H}^{\prime}+X_{R}^{\prime}+X_{P}^{\prime}\right) \frac{\rho}{2} L d U^{2} \\
Y=\left(Y_{H P}^{\prime}+Y_{R}^{\prime}\right) \frac{\rho}{2} L d U^{2} \\
N=\left(N_{H P}^{\prime}+N_{P}^{\prime}+N_{R}^{\prime}\right) \frac{\rho}{2} L^{2} d U^{2}
\end{array}\right.
$$

where,

$$
\begin{aligned}
& \text { subscripts } H: \text { hull } \\
& \text { subscripts } P: \text { propeller } \\
& \text { subscripts } R: \text { rudder. }
\end{aligned}
$$

For $Y$ and $N$, however, it is difficult to separate the contribution of hull and propeller; these force components are expressed as $Y_{H P}^{\prime}$, and $N_{H P}^{\prime}$, respectively. 


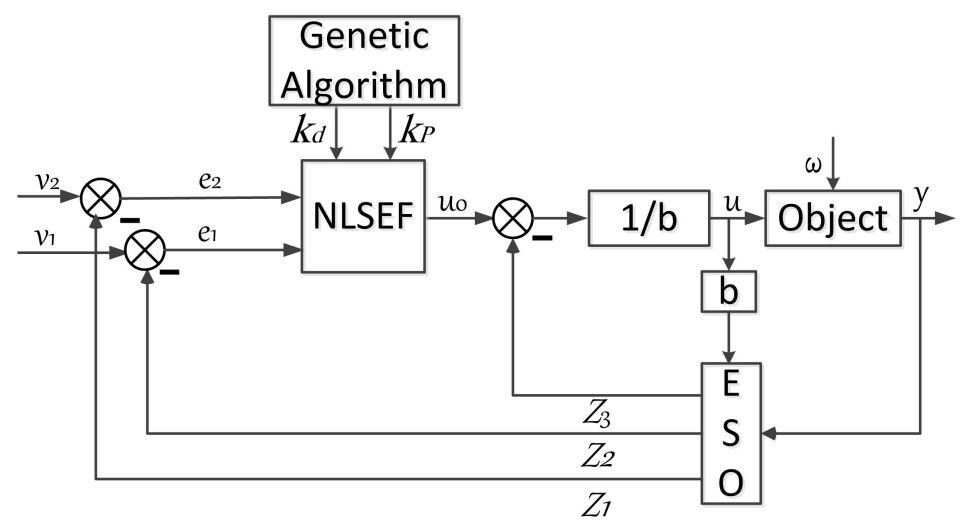

Fig. (1). Genetic Algorithm ADRC.

\subsection{Disturbance Model}

In this article, uniform random wave disturbance is used only for the display is as follows:

$\omega=\left(4.58 H_{1}+3.44 H_{2}\right)^{\circ}$

Where $H_{1}$ and $H_{2}$ are of the uniform distribution $\mathrm{U}(0,1)$.

\section{TWO-ORDER ADRC}

ADRC controller consists of three main parts: "Tracking Differentiator (TD)", "Non-linear Feedback (NF)" and "Extended State Observer (ESO)".

\section{IMPROVE ADRC CONTROLLER}

There is a great relationship since the performance of the anti-rejection controller and its parameters is determined by experiment choice. Extensive simulation studies show that ADRC is entirely based on the "separability" design principle, namely, a part of individually designed TD ESO and error feedback, combined into a complete ADRC. Many of the parameters used are the same parameters, as well as stock options. Three parameters can be automatically generated, as they are just manually set. So, in order to overcome the inconvenient changes in practice and parameters, the use of genetic algorithms is advised, which is a control method. In this method, parameters can be automatically adjusted. The genetic algorithm controller design is automatic and based on approximation and optimization and parametric input. Adaptive interference suppression parameters line changes according to the rules of the genetic algorithm, to meet the different requirements of the time and improve ADRC control performance. Based on the above analysis, the design structure of ADRC genetic algorithm is shown in Fig. (1).

Where, $\mathrm{v}$ is the control objective, $v_{l}$ is the track signal of $v, v_{2}$ is differential signal of $v, z_{1}, z_{2}$ are the estimation of output $y$ and its differential, $z_{3}$ is the estimation of total disturbance; $e_{1}, e_{2}$ are the error, $u_{0}$ is the output of NF, $b$ is the estimation of $b(t)$.
Using genetic algorithm to solve the optimization problem that needs to be addressed when coding scheme of genetic manipulation methods, adapt to the function set which is very important because it judges the individual's ability to adapt to the rules to ensure that the best individual reflects the solution of optimization that problem is the key. The fitness function is closely related to the specific research questions, and it should be the essence of the problem and easy to calculate.

\section{1) Optimization of objective function}

Aiming at the problem of optimization of ADRC, a control system for comprehensive evaluation of the dynamic performance and static performance (e.g., response speed, regulating time, overshoot and steady-state error) based on the principle of minimum energy consumption, i.e. the target function, this paper selected error absolute value of time integral performance index of ITAE and control volume, namely:

$$
J(e)=\int_{0}^{t}\left(\tau\left|y\left(\tau-v_{0}\right)\right|+|u|\right) d \tau
$$

The fitness function is reciprocal. The optimal control parameter is the controller parameters corresponding to the maximum fitness function.

\section{2) Coding and genetic manipulation}

Coding: the individual coding format uses real number coding, which can avoid the common binary form needs to encode and decode the trouble. The expression of the individual is composed of ADRC parameters $\left\{k_{p}, k_{d}\right\}$.

Genetic operation: a simple single point cross way. Variation of adaptive variation. When the adaptation degree is high, the mutation rate is decreased. When the adaptation degree is low, the mutation rate is increased. Choose the right proportion of common choice and optimal retention strategy. Elitist strategy can guarantee the failure; so far the best individual will not be crossover and mutation of genetic operation. This and other ways of selecting a match ensures that the genetic algorithm global search guarantees an optimal value. 

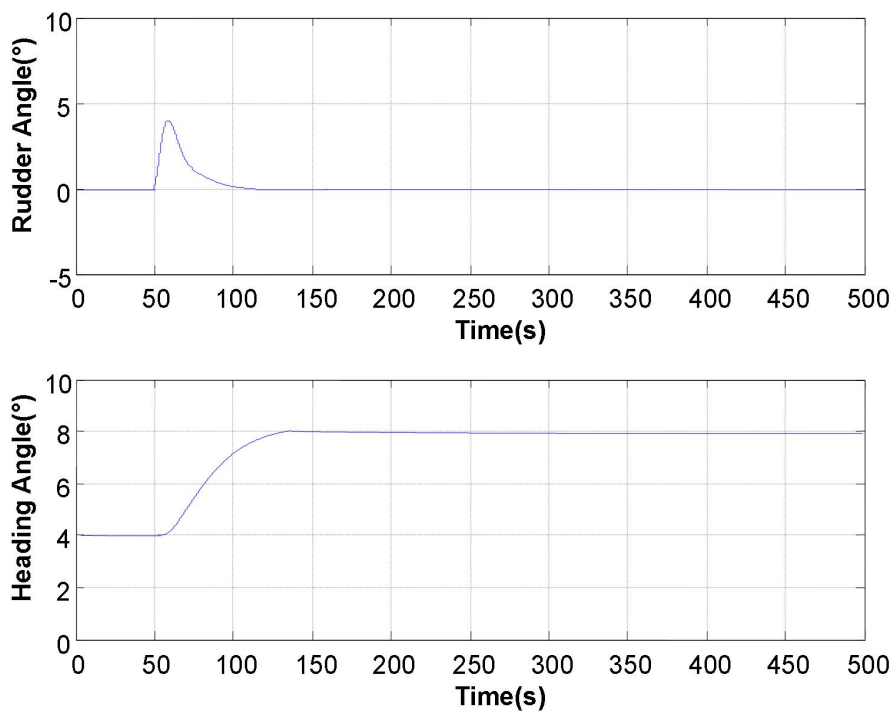

Fig. (2). Change course from 4 degrees to 8 degrees simulation results under normal operational conditions.
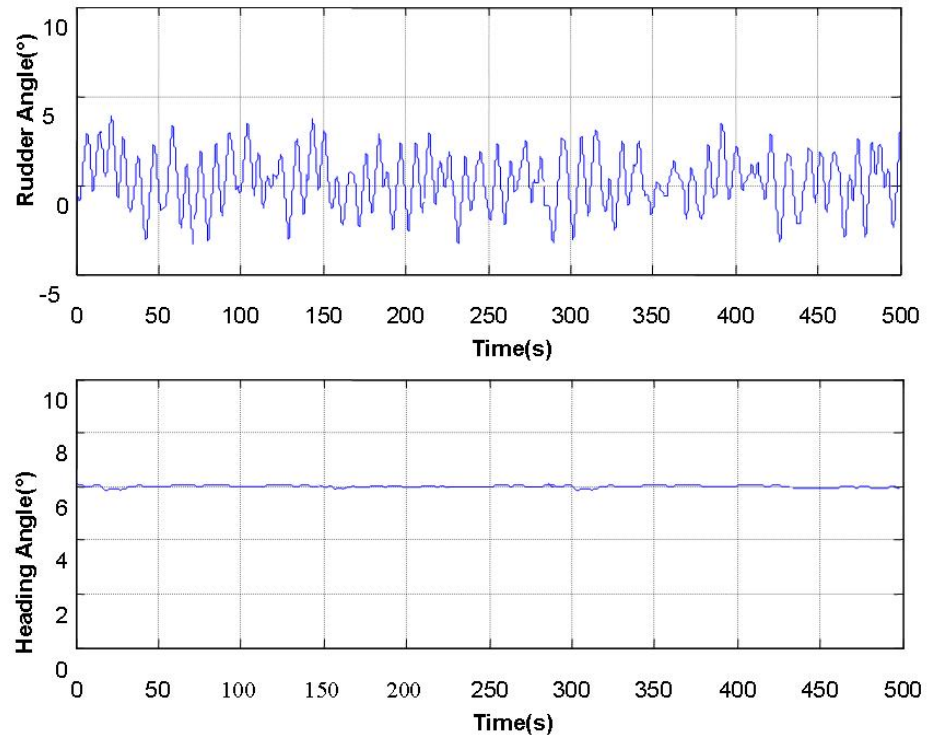

Fig. (3). Course setting 6 degree simulation results in random distribution perturbation.

\section{SIMULATION RESULTS}

Due to space limitations, only two simulation results are possible (Figs. 2, 3).

From the two pictures, we can come to a conclusion:

1) dynamic accuracy (conversion) process control and static accuracy (heading) is a small time course with very high conversion angle.

2) Under normal working conditions, set the course change, the rudder angle tracking is quick and the change is small, the heading tracking is fast and accurate. In the case of uniform random disturbance, although the rudder angle change is frequent yet the heading tracking is still accurate.
So, the newly designed yacht course controller has strong non-linear robustness under parameters and conditions of uncertainty; course tracking is fast and smooth, so as to achieve high-precision yacht curriculum objectives.

\section{CONCLUSION}

A new non-linear GA ADRC yacht course controller is designed. It is strictly robust having non-linear characteristics of the yacht; and parameter perturbations and uncertainty disturb the system, and the system is not dynamic modeling. Under normal working conditions, set the course change, the rudder angle tracking is quick and the change is small, whereas the heading tracking is fast and accurate. In the case of uniform random disturbance, although the rudder angle is 
frequent yet the heading tracking is still accurate. So, it is perfect as a yacht heading controller.

\section{CONFLICT OF INTEREST}

The authors confirm that this article content has no conflict of interest.

\section{ACKNOWLEDGEMENTS}

This work was financially supported by the Chinese Shandong Province Natural Science Fund Project (Number: ZR2013ZEM006), China Department of transportation Project (Number: 2014329817130) and Department of transportation of Shandong province Chinese Project (Number: 2013A16-04).

\section{REFERENCES}

[1] J. Q. Han, "From PID technique to active disturbance rejection control technique", Control Engineering of China, vol. 9, no. 3, pp. 13-18, 2002.

[2] J. Q. Han, "Auto disturbances rejection control technique", Frontier Science, vol. 1, pp. 24-31, 2007.

[3] X. R. Zhao, Y. Zheng, and Y. H. Hou, "The rational spectrum modeling of the ocean wave and its simulation method", Journal of System Simulation, vol. 4, no. 2, pp. 33-39, 1992.

[4] Y. H. Hu, and X. L. Jia, "Theory and application of predictive control of ships subject to state constraints", Control and Decision, vol. 17 , no. 4 , pp. 542-547, 2000.

[5] X. C. Wang, X. H. Jiang, and J. Zhang, "Linear backstepping design of ship maneuvering controller", Control Engineering, vol. 9, no. 5 , pp. $63-65,2002$.

[6] X. K. Zhang, and X. L. Jia, Ship Motion Control. National Defense Industry Press, Beijing, China, 2006.

(c) Weigang and Hairong; Licensee Bentham Open.

This is an open access article licensed under the terms of the (https://creativecommons.org/licenses/by/4.0/legalcode), which permits unrestricted, non-commercial use, distribution and reproduction in any medium, provided the work is properly cited. 